\title{
Autologous rabbit adipose tissue-derived mesenchymal stromal cells for the treatment of bone injuries with distraction osteogenesis
}

\author{
OZGUR SUNAY ${ }^{1}$, GEYLANI CAN ${ }^{3}$, ZEYNEP CAKIR $^{3}$, ZIYA DENEK $^{2}$, \\ ILKNUR KOZANOGLU ${ }^{4}$, GUVEN ERBIL ${ }^{2}$, MUSTAFA YILMAZ $^{1} \&$ YUSUF BARAN $^{3}$
}

Departments of ${ }^{1}$ Plastic Reconstructive and Aesthetic Surgery and ${ }^{2}$ Histology and Embryology, Dokuz Eylul University, School of Medicine, Balcova, Izmir, ${ }^{3}$ Department of Molecular Biology and Genetics, Izmir Institute of Technology, Faculty of Science, Urla, Izmir, and ${ }^{4}$ Adana Teaching and Medical Research Center, Bone Marrow Transplantation Unit, Baskent University, School of Medicine, Adana, Turkey

\begin{abstract}
Background aims. Adipose tissue-derived mesenchymal stromal cells (MSCs) have a higher capacity for proliferation and differentiation compared with other cell lineages. Although distraction osteogenesis is the most important therapy for treating bone defects, this treatment is restricted in many situations. The aim of this study was to examine the therapeutic potential of adipose tissue-derived MSCs and osteoblasts differentiated from adipose tissue-derived MSCs in the treatment of bone defects. Methods. Bone defects were produced in the tibias of New Zealand rabbits that had previously undergone adipose tissue extraction. Tibial osteotomy was performed, and a distractor was placed on the right leg of the rabbits. The rabbits were placed in control (group I), stem cell (group II) and osteoblast-differentiated stem cell (group III) treatment groups. The rabbits were sacrificed, and the defect area was evaluated by radiologic, biomechanical and histopathologic tests to examine the therapeutic effects of adipose tissue-derived MSCs. Results. Radiologic analyses revealed that callus density and the ossification rate increased in group III compared with group I and group II. In biomechanical tests, the highest ossification rate was observed in group III. Histopathologic studies showed that the quality of newly formed bone and the number of cells active in bone formation were significantly higher in group III rabbits compared with group I and group II rabbits. Conclusions. These data reveal that osteoblasts differentiated from adipose tissue-derived MSCs shorten the consolidation period of distraction osteogenesis. Stem cells could be used as an effective treatment for bone defects.
\end{abstract}

Key Words: adipose tissue-derived mesenchymal stromal cells, bone defects, distraction osteogenesis, FACS, GFP, regenerative medicine

\section{Introduction}

Bone defects generally occur as a result of gunshot wounds or traffic accidents (1). They can also occur after open fractures secondary to high-energy trauma, malignancy and infections. Various methods are used to treat bone defects. The main treatment techniques are autogenous spongious bone grafts, free vascular pedicle bone grafts, demineralized allograft application, prosthesis application and distraction osteogenesis $(2,3)$. All of these surgical procedures have disadvantages that restrict their usage. However, distraction osteogenesis has special importance because it has the ability to repair large defects, satisfies the principles of natural bone formation processes and is known to be autogenous (3).

The major disadvantage of distraction osteogenesis is the prolonged treatment period, which gives rise to various complications such as fibrous knitting, formation of an un-knit bone, collapse of the callus, loss of elongation or improper knitting of the bone $(4,5)$. Various methods have been investigated to enhance the formation of callus and shorten the duration of consolidation. Commonly used methods are low-energy ultrasound, electrical stimulation, growth factors, prostaglandin $\mathrm{E}_{2}$, bone marrow extracts, demineralized bone matrix, bone morphogenetic protein 7 (osteogenic protein 1) and transforming growth factor- $\beta(6-14)$.

Because the outcomes of these treatment methods are limited or inadequate, to enhance new bone formation in distraction osteogenesis, mesenchymal stromal cells (MSCs) hold great promise in the area of regenerative medicine (15). However,

Correspondence: Dr Yusuf Baran, Department of Molecular Biology and Genetics, Izmir Institute of Technology, Faculty of Science, Gulbahce Campus, 35430 Urla, Izmir, Turkey. E-mail: yusufbaran@iyte.edu.tr 
Table I. Study groups and animal numbers.

\begin{tabular}{lcccccccc}
\hline Group & Total & GFP & Stem cell & $\begin{array}{c}\text { Differentiated } \\
\text { stem cell }\end{array}$ & $\begin{array}{c}\text { Biomechanical } \\
\text { analysis }\end{array}$ & $\begin{array}{c}\text { Histologic } \\
\text { analysis }\end{array}$ & $\begin{array}{c}\text { Radiologic } \\
\text { analysis }\end{array}$ & $\begin{array}{c}\text { Immunohistochemical } \\
\text { analysis }\end{array}$ \\
\hline I (control) & 7 & 0 & 0 & 0 & 3 & 7 & 7 & 7 \\
II (stem cell) & 7 & 7 & 7 & 0 & 3 & 7 & 7 & 7 \\
III (differentiated & 7 & 7 & 0 & 7 & 3 & 7 & 7 & \\
$\quad$ stem cell) & 21 & 14 & 7 & 7 & 9 & 21 & 21 & \\
Total & & & & & & & & 21 \\
\hline
\end{tabular}

sources of stem cells are limited, and they have their own disadvantages. Stem cell isolation from bone marrow is generally a very painful process that requires general anesthesia; also, the number of stem cells acquired is insufficient (16-19). To obtain MSCs from sources other than the bone marrow, adult tissues such as muscle, perichondrium and adipose tissue can also be used (20-23). Adipose tissue harbors multi-potent stem cells, which reside within the stromal region and possess developmental plasticity similar to bone marrow cells $(24,25)$. Adipose tissue-derived MSCs are more advantageous compared with other MSCs because they can be easily isolated from the tissue and produced in large numbers in cell culture and frozen in stem cell banks without losing their phenotypic and genotypic characteristics (26). Adipose tissue-derived MSCs have been shown to be converted into adipose tissue, muscle, cartilage, neuron and bone cells under appropriate differentiation conditions (27).

Natural healing of a fracture proceeds from multi-potent osteoprogenitor cells, which reach the fractured region and have a multi-potential capacity to differentiate into osteoblasts (28). The aim of this study was to analyze the effects of administration of adipose tissue-derived MSCs and osteogenically differentiated stem cells on the distraction process.

\section{Methods}

\section{Animal care}

For this study, 21 adult female New Zealand white rabbits weighing $2.5-3.5 \mathrm{~kg}$ were used (Table I). All animal experiments undertaken in this study were performed in accordance with the protocols approved by the Institutional Animal Care Committee. Rabbits were anesthetized with intramuscular injection of ketamine $(35 \mathrm{mg} / \mathrm{kg}$ ) and xylazine chloride $(5 \mathrm{mg} / \mathrm{kg})$. A single dose of cefazolin was also administered as a prophylactic antibiotic.

\section{Equipment used in animal studies}

Distractors were designed specifically for this experiment and were of the Ilizarov type with two rings and three bars. The external and internal diameters were
7.5 and $5.5 \mathrm{~cm}$, respectively, and the thickness of the rings was $0.5 \mathrm{~cm}$. The total weight of the distractor was $100 \mathrm{~g}$ (see Supplementary Figure 1A) and the Kirschner wire used in the experiments was $1 \mathrm{~mm}$ in diameter and $30 \mathrm{~cm}$ in length.

\section{Groups}

In this study, 21 rabbits were divided into three groups-one control and two experimental groups. In group I (control), the Ilizarov distractor was mounted on the right tibia of the rabbits, and osteotomy was performed. Following a 7-day latent period, distraction was carried out for 15 days $(0.7 \mathrm{~mm} /$ day); a 10-mm distraction was obtained. In group II (MSC group), $30 \mathrm{~mL}$ of adipose tissue were extracted from both inguinal regions of the rabbits, and adult multipotent stem cells were generated. The surfaces of the resulting cells were labeled by specific markers, counted by flow cytometry (fluorescence-activated cell sorter [FACS]) and shown to be MSCs. Next, stem cells were labeled by green fluorescent protein (GFP) for histologic follow-up within the distraction environment. The circular distractor was mounted on the right tibia of the rabbits. Within 15 days after the completion of the distraction period, at the beginning of the consolidation phase, $5 \times 10^{6}$ adipose tissuederived adult stem cells were injected into the smooth callus area under the field of radiologic imaging. In group III (osteoblast differentiated MSC group), stem cells generated as in group II were obtained and labeled with GFP. GFP-labeled stem cells were then stimulated to undergo osteogenic differentiation. Differentiation was confirmed using alizarin red dye, which stains the calcium deposits, and $5 \times 10^{6}$ differentiated stem cells were injected into the smooth callus area within the osteotomy line.

\section{Follow-up}

After a 7-day latent period, $0.7 \mathrm{~mm} /$ day distraction was applied to all rabbits for 15 days. After the completion of $10 \mathrm{~mm}$ of distraction, all groups were monitored for 8 weeks. After the completion of distraction, the rabbits were examined weekly by $\mathrm{x}$-ray, and elongation and ossification status in the 
bones were assessed. The animals sacrificed after the consolidation period were evaluated by histopathologic, biomechanical and radiologic examinations.

\section{Surgery and distraction protocol}

To obtain adipose tissue, the rabbit was placed in the supine position on the operating table. After appropriate sterilization, prilocaine hydrochloride (AstraZeneca, Istanbul, Turkey) infiltration $(1 \mathrm{mg} / \mathrm{kg})$ was performed. An incision was made combining both inguinal regions of the rabbit. After elevation of the skin flaps, the inguinal adipose pads were excised. After washing with sterile saline, $30 \mathrm{~mL}$ of excised adipose tissue was transferred into a sterile container.

For installation of distractors, the rabbit was placed in the supine position and covered with a sterile operating blanket in a position so as to leave its lower right extremity available. Analgesia and antibiotic prophylaxis were administered using a $2-\mathrm{mL}$ infusion of Citanest and cefazolin. The first 1-mm diameter Kirschner wire was placed percutaneously and perpendicular to the tibia with 90 degrees with a Dremel (Racine, WI, USA) charged engine. The second Kirschner wire was also placed percutaneously and perpendicular to the first wire and $0.5 \mathrm{~cm}$ distal to the first wire (up to distractor ring thickness). A third Kirschner wire $1.5 \mathrm{~cm}$ distal to the second wire and a fourth Kirschner wire 0.5 $\mathrm{cm}$ distal to the third wire were placed percutaneously. After placement of the Kirschner wires, the first Ilizarov ring was placed between the top two Kirschner wires (see Supplementary Figure 1C). Rings were placed on the Kirschner wires. Using spacers and bolt nuts, $0.5-\mathrm{cm}$ diameter screws with $1.5-\mathrm{mm}$ diameter holes on their necks were placed tightly. Following placement of the Ilizarov rings, three grooved bars $0.5 \mathrm{~cm}$ in diameter and $6 \mathrm{~cm}$ long were placed at equal intervals to fix each ring together (see Supplementary Figure 1B).

The osteotomy phase started after mounting the distractor. A $2-\mathrm{cm}$ vertical skin incision was made from the anteromedial region of the tibia. The periosteum was reached via the medial surface by dissecting in between the tibialis cranialis and extensor digitorum muscles. The periosteum was scratched and elevated in a preserved condition, and the area was revealed for the osteotomy. Next, the osteotomy was performed from the distal region of the tibiofibular component (see Supplementary Figure 1D). The bone was continuously washed with sterile saline to protect it from the high temperature during osteotomy. After completion of the osteotomy, the periosteum and the soft tissues were sutured. A closed dressing was completed by applying povidone-iodine and mupirocin pomade. To protect the surgical site and distractor, after medical dressing, the right lower extremity of the rabbit was placed into a cotton sack that was developed for this study (29).

\section{MSCs isolation and cultivation}

Adipose tissue was obtained from the inguinal area of the rabbits and placed into two sequential Petri dishes containing $5 \mathrm{~mL}$ phosphate-buffered saline ( $2 \%$ penicillin and streptomycin). Collagenase type I $(0.075 \%)$ was used to isolate MSCs.

For flow cytometry, the antibodies used for phenotypic characterization of MSCs were antiCD45 APC-Cy7 (BD Biosciences Pharmingen, San Diego, CA, USA), anti-NG2 PE (Beckman Coulter, Marsellia, France), anti-CD73 PE (BD Biosciences Pharmingen), anti-CD34 PE-Cy7 (BD Biosciences, San Diego, CA, USA) and anti-CD105 FITC (Serotec, Oxford, UK). A BD FACSCanto-II flow cytometer (BD Biosciences Pharmingen) was used, and cells were analyzed using BD FACS DiVa software (BD Biosciences Pharmingen) as previously described $(30,31)$.

To track the MSCs in vivo, cells were transfected with the pEGFP-N1 vector including GFP as the encoded reported gene (Clontech Laboratories, Mountain View, CA, USA). Lipid-based transfection was performed with the PolyFect Transfection Reagent as described elsewhere (Qiagen, Valencia, CA, USA) (32).

For osteogenic differentiation of MSCs, after the third passage of MSCs, an osteogenic supplement $(15 \%$ osteogenic supplement, $3.5 \mathrm{mmol} / \mathrm{L}$ $\beta$-glycerophosphate, $0.01 \mu \mathrm{mol} / \mathrm{L}$ dexamethasone and $50 \mu \mathrm{g} / \mathrm{mL}$ ascorbic acid) was added to MesenCult MSC Basal Medium (Stem Cell Technologies, Vancouver, BC, Canada) (33).

To examine the deposition of calcium hydroxyapatite in osteogenic differentiated MSCs, cells were treated with alizarin red as described previously (33).

The injection protocol was as follows: $5 \times 10^{6}$ stem cells were suspended in $0.25 \mathrm{~mL}$ sterile saline and were slowly injected into the distraction area for $1 \mathrm{~min}$ using a 26-gauge needle (see supplementary Figure 2). After the injection, the needle was kept inside the area for $1 \mathrm{~min}$ to prevent leakage of the sample.

\section{Radiologic observation and analysis}

Samples were visualized using a high-resolution digital radiography system (Philips Digital Diagnost; Philips Medical Systems, Seattle, WA, USA). Imaging was standardized from a distance of $110 \mathrm{~cm}$ using $66 \mathrm{kV}, 1.82 \mathrm{msn}, 1.20 \mathrm{mAs}$ and $\mathrm{X} 1$ magnification. The density of the distraction area containing the newly formed bone was determined, and scoring 
was performed using the modified Lane and Sandhu scoring system.

\section{Biomechanical analysis}

After completion of the radiologic analyses, three animals from each group were randomly chosen and sacrificed in week 8 . The distraction area was cooled with sterile saline provided $2 \mathrm{~cm}$ from its proximal and distal regions and cut with a high-speed electric cutter. For the biomechanical studies, the 3-point bending test was applied (AG-I $10 \mathrm{kN}$, Shimadzu, Japan). After fixation of the bottom apparatus at a distance of $30 \mathrm{~mm}$, the bone samples were placed into the region where the distracted area was centered into the top apparatus. The bending test was carried out by pressing at the samples at $1 \mathrm{~mm} / \mathrm{min}$. Fracture strength was determined as the maximum load sustained by each bone.

\section{Histologic observation and histomorphometric analysis}

The samples were numbered and fixed using 10\% formaldehyde at room temperature for $24-48 \mathrm{~h}$. The tibias were placed into Morse solution for decalcification. The Morse solution was prepared by mixing $10 \%$ buffered formalin and $20 \%$ formic acid. After the staining procedures, samples were examined using light microscopy. A DX51 fluorescent microscope (Olympus, Center Valley, PA, USA) was used for histologic analyses. Osteocytes, osteoblasts, osteoclasts, fibroblasts and chondrocytes were counted per square millimeter in six different areas using iron hematoxylin preparations $(34,35)$. In the histopathologic examinations, images taken under $1 \times$ magnification using a light microscope were transferred to the computer using a color digital DC70 video camera (Olympus). For visualization, Image-Pro Plus software (Media Cybernetics, Rockville, MD, USA) was used. The areas of the newly formed trabecular and cartilage regions were calculated in a digital environment (ImageTool 3.0 software, UTHSCA, San Antonio, TX, USA). To observe emission of the GFP-labeled cells, samples from group II and group III were analyzed using a fluorescent microscope. Cells positive for osteocalcin and osteopontin were counted per square millimeter in six different areas in the samples prepared by immunohistochemical staining (36).

\section{Statistical analysis}

The results of the radiologic and biomechanical analyses and the histomorphometric measurements obtained from the operated rabbits in the study were analyzed using the SPSS 15.0 (IBM, Armonk, NY,
USA) statistical program for Windows using the Mann-Whitney $U$ test. Data are shown as mean ( \pm standard deviation).

\section{Results}

\section{Clinical evaluation}

All the animals tolerated the distractor and easily reached food and water. Postoperative edema and hyperemia occurred in three rabbits, which regressed within 1 week. One rabbit in group III developed lower extremity paralysis after the extraction of adipose tissue. This rabbit was considered to be invalid and replaced with an alternative one, and the study was completed with 21 rabbits.

\section{Isolation, differentiation, characterization and GFP transfection of MSCs}

MSCs were successfully isolated from the adipose tissue of New Zealand rabbits (see Supplementary Figure 3A) and labeled with GFP to track the MSCs in vivo (see Supplementary Figure 3B). Differentiation of MSCs, obtained from the animals in group III, into osteoblasts was assessed by alizarin red staining as shown in Supplementary Figure 3C. To prove that the isolated cells were MSCs, flow cytometry analysis was conducted with antibodies specific for MSCs (CD73, CD105 and NG2) and hematopoietic stem cells (CD34 and CD45). Flow cytometry analyses revealed that CD73, CD105 and NG2 specific for MSCs were $99 \%$ positive (Figure 1A,B,D), whereas the markers specific for hematopoietic stem cells, CD34 and CD45, were negative (Figure 1C,D) in isolated MSCs.

\section{Radiologic observation and analysis}

The radiologic imaging results of the rabbits immediately after the completion of the latent period (at the beginning of the consolidation phase) and the radiologic images taken in weeks 4 and 8 of the consolidation period were compared. In two rabbits belonging to group III, which received osteogenically differentiated MSCs, the distraction field was observed to be filled in with callus to approximately $100 \%$ (Figure 2). This ratio was found to be lower in group II, which received the undifferentiated MSCs. When compared with the differentiated stem cell group, the fibrous inter-zone was less ossified and less mineralized in the control group and stem cell group, and filling in the form of bridge was less in the woven bone (Figure 2). Callus tissues in the control group were significantly radiolucent; this can be explained by less mineralization. In addition, 

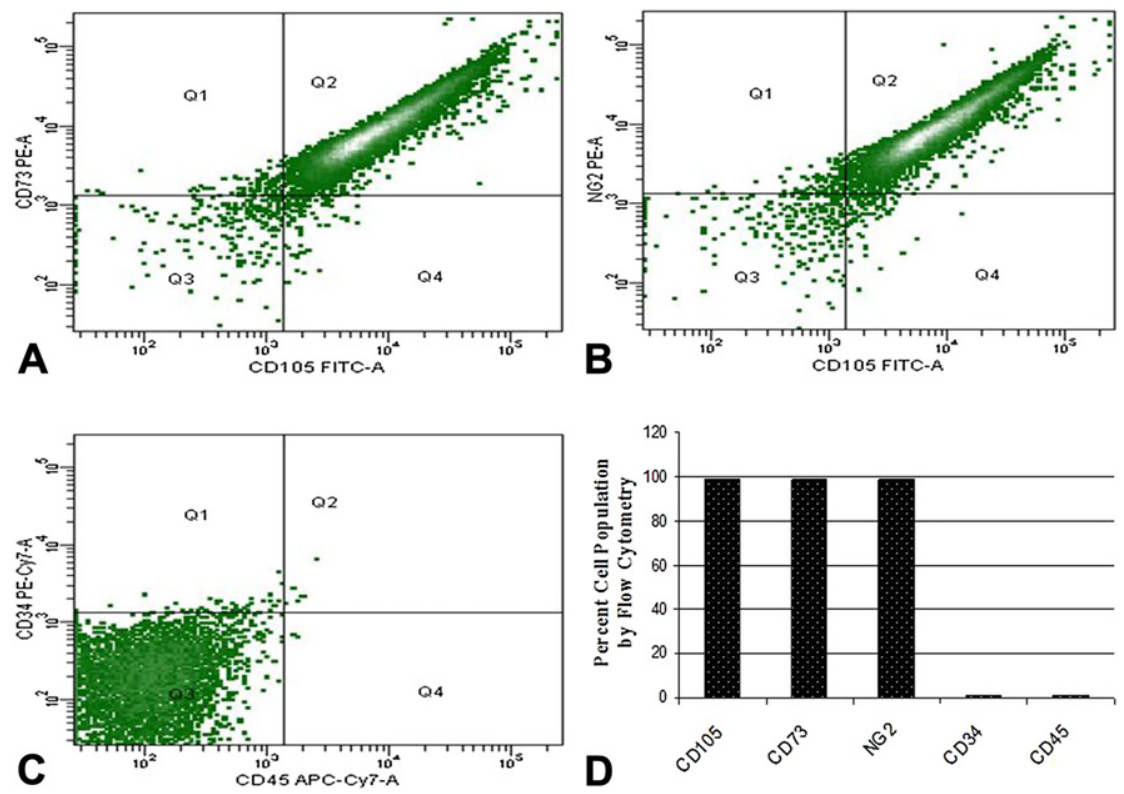

Figure 1. (A-D) Expression levels of MSC-specific CD105, CD73 and NG2 (A, B, D) and hematopoietic specific CD34 and CD45 (C, D) markers.

especially compared with group III, bridging was insufficient, and callus occupancy rates were much lower. For the evaluation of the radiographic images of the animals, the modified Lane and Sandhu scoring system was used $(37,38,52,53)$. The scores in each group and the occupancy rate of the distraction field with the callus tissue were compared.
Lane and Sandhu scores in groups I, II and III were $4.571,5.14$ and 6.14 , respectively (Figure 3A). Following the binary comparison of each group with other groups, the difference between group I and group II $(P=0.044)$ and group I and group III $(P=0.011)$ was found to be statistically significant. However, the difference between group II and group
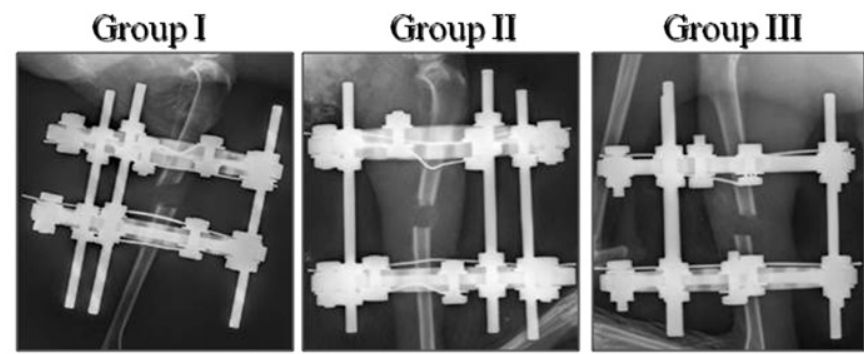

Consolidation

on the 1 st week
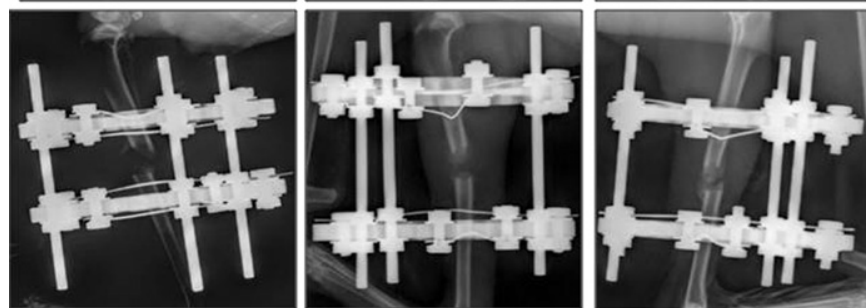

Consolidation

on the 4 th week
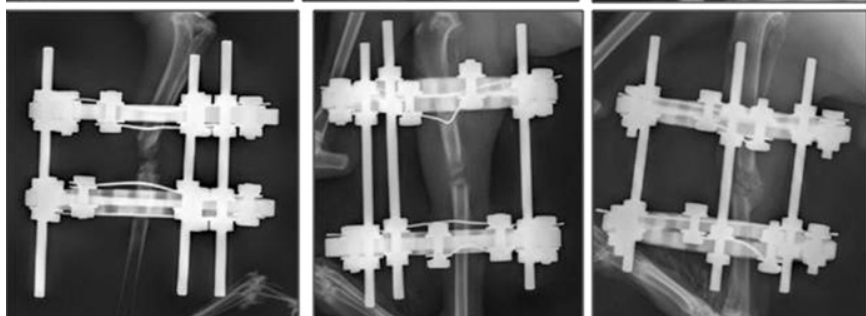

Consolidation

on the 8th week

Figure 2. Radiologic analyses of bone formation for groups I, II and III 


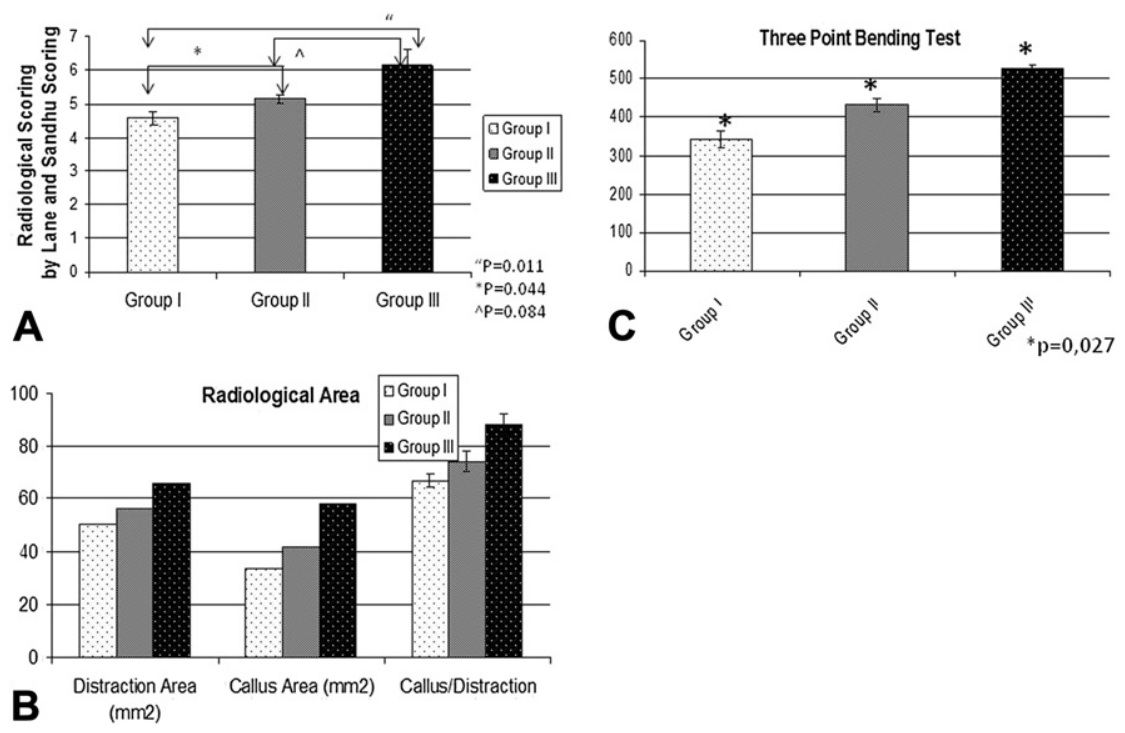

Figure 3. (A) Radiologic scores by Lane and Sandhu scoring, (B) radiologic areas of distraction and callus in square millimeters and (C) 3-point bending test results.

III was statistically insignificant $(P=0.084)$. Following radiologic evaluation of the rabbits, the ratios of the ossified callus occupying the distraction field were observed to be $66.7,74.1$ and 88.5 in groups I, II and III, respectively (Figure 3B). In the statistical comparison, the difference between group I and group II was insignificant $(P=0.18)$. However, the difference between group I and group III $(P=0.002)$ and group II and group III $(P=0.047)$ was statistically significant.

\section{Biomechanical evaluation and analysis}

Following the comparison of the results obtained from the 3-point bending test used for biomechanical evaluation, the highest scores were observed in group III (Figure 3C). The mean values of groups I, II and III were confirmed to be $344.1 \mathrm{~N} / \mathrm{mm}^{2}, 433.3$ $\mathrm{N} / \mathrm{mm}^{2}$ and $526.9 \mathrm{~N} / \mathrm{mm}^{2}$, respectively (Figure 3C). Using the Kruskal-Wallis test, which was applied for the evaluation of the differences between groups, the significance was $P=0.027$. The difference in this evaluation was statistically significant.

\section{Histopathologic results}

Fracture healing and callus formation depend on several factors, such as the formation of a less traumatic fracture, the absence of free fragments, and the quality and angle of the fixation (39). Because the fracture in our study occurred as the result of a minor trauma, sections derived from the fracture line were not observed to contain any free fragments. The broken ends of the bone showed hypercellular fibroblastic activity, and the characteristic bone models were represented by hyaline cartilage islands at vascularized medullary sites (34).

Following the analyses of the cross-sections belonging to group I, endochondral ossification emerging from the fracture line was observed, and trabecula formation was detected at a low rate. Most of the callus tissue was observed to consist of multicellular (regenerative) connective tissue, and cartilage areas between cells were encountered in abundance (Figure 4A,B) $(34,35)$.

On examination of the sections belonging to group II, secondary ossification was shown to have occurred at a higher rate compared with group I, and a decline in the ratio of the connective tissue was found. Growth of the trabecular structure and its tendency to develop a regular network was observed. Most of the callus tissue was shown to be composed of trabecular bone and cartilage tissue islets (Figure 4C,D) (35).

Following examination of the cross-sections from group III, ossification starting from the fracture line was shown to have progressed at a much higher rate compared with group I and II, and a significant decrease in the connective tissue ratio was detected. Augmentation of a regular trabecular structure was observed, and most of the callus tissue was discovered to be composed of trabeculae and cartilage tissue (Figure 4E,F) (34,35).

On analysis of the GFP-labeled cells in group II and group III by fluorescent microscopy, the 8-weeklong consolidation period and the Morse solution used for de-calcification of the bone at the end of this period were not shown to have a negative effect on the fluorescent emission. GFP-marked cells were found to be alive and emitting signal, and their 

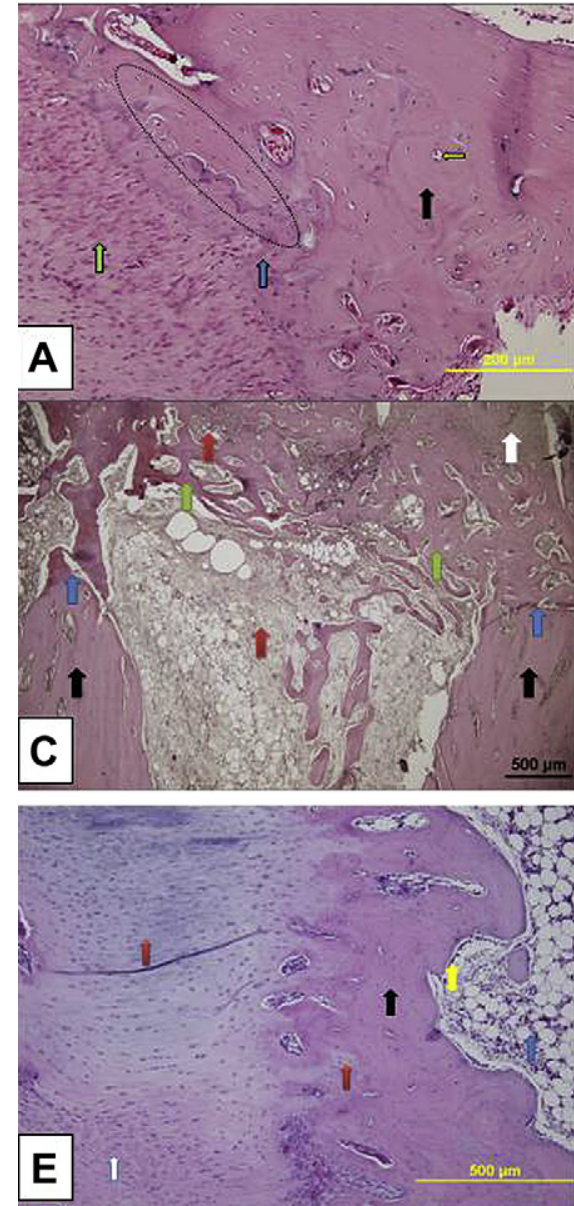
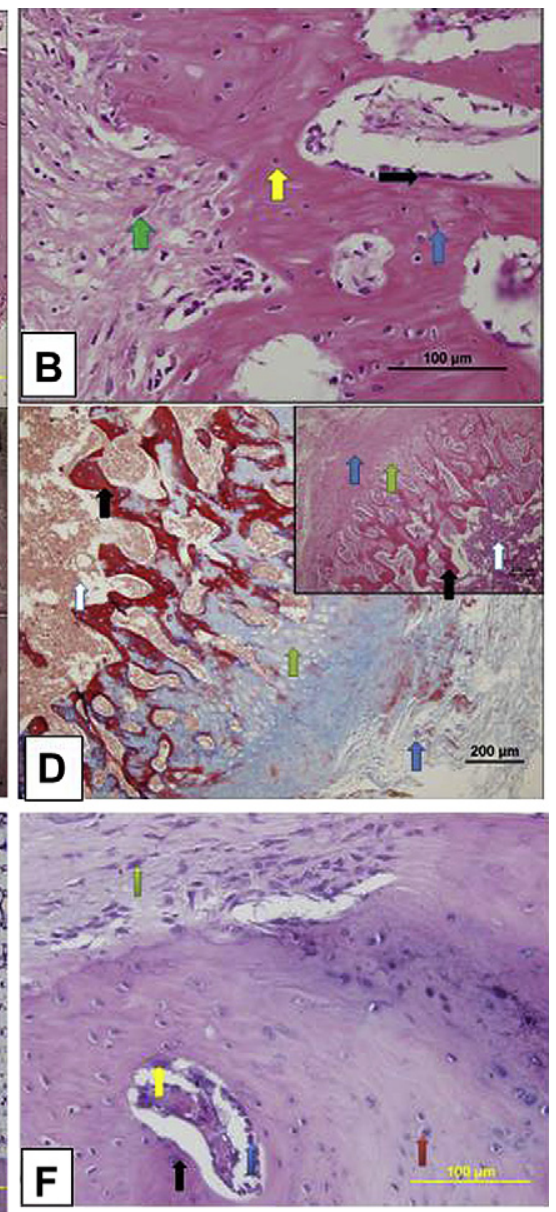

Figure 4. Histopathologic results of group I (A, B), group II (C, D) and group III (E, F) by hematoxylin and eosin staining. (A) Group I. Osteon (black arrow), haversian canal (yellow arrow), cartilage focal points (blue arrow), cartilage areas (dotted area), hypercellular connective tissue (green arrow). (B) Group I. Left, Hypercellular connective tissue containing abundant numbers of fibroblasts. Right, Islets of cartilage tissue in the bone network. Osteoblast (black arrow), cartilage focal points (blue arrow), osteocyte (yellow arrow), fibroblast in the connective tissue (green arrow). (C) Group II. Two cortical bone fractures and medulla in between these fractures are observed in the lower right and left. These two points continue with a considerably tight, web-like trabecular bone network. Tip of the fracture (black arrow), fracture line (blue arrow), newly forming trabecula (green arrow), bone marrow (red arrow), hypercellular connective tissue (white arrow). (D) Group II. Newly forming trabeculae (black arrow), cartilage transition (green arrow), connective tissue (blue arrow), bone marrow (white arrow). (Masson's trichrome and hematoxylin and eosin.) (E) Group III. Newly forming trabecular bone tissue (black arrow), cartilage tissue (red arrow), hypercellular connective tissue (white arrow), bone marrow (blue arrow). (F) Group III. Osteocyte (black arrow), chondrocyte (red arrow), osteoblast (blue arrow), osteoclast (yellow arrow), fibroblast (green arrow).

integration into the bone and cartilage and homing in to the callus tissue was found to enhance the recovery period.

A portion of the stem cells that were applied into the fracture line in group II was observed to be undifferentiated, whereas another portion was shown to be differentiated into non-osteogenic cells such as fibroblasts (Figure 5A,B). In group III, most cells that had differentiated into osteocytes were observed to be involved in bone repair (Figure $5 \mathrm{C}-\mathrm{E}$ ).

\section{Histologic digital evaluation}

When the average number of osteocytes and chondrocytes in square millimeters was analyzed, there was a significant increase numerically and statistically in group II and group III compared with group I $(P=0.0001$ and $P=0.0002$, respectively, Figure 6A). When the number of osteoblasts was analyzed, the highest value was in group III as the average number of osteocytes in square millimeters, and although there was no significant difference between group I and group II $(P=0.9)$, there was a statistically significant difference between group I and group III $(P=0.0001)$. The highest average fibroblast value showed the lowest ossification, and as expected, the highest fibroblast values were in group I. There was a statistically significant decrease in the number of fibroblasts in group II and group III compared with group I $(P=0.0002$ and $P=0.0009$, respectively). The highest average osteoclast values were in group I, and a statistically significant increase 


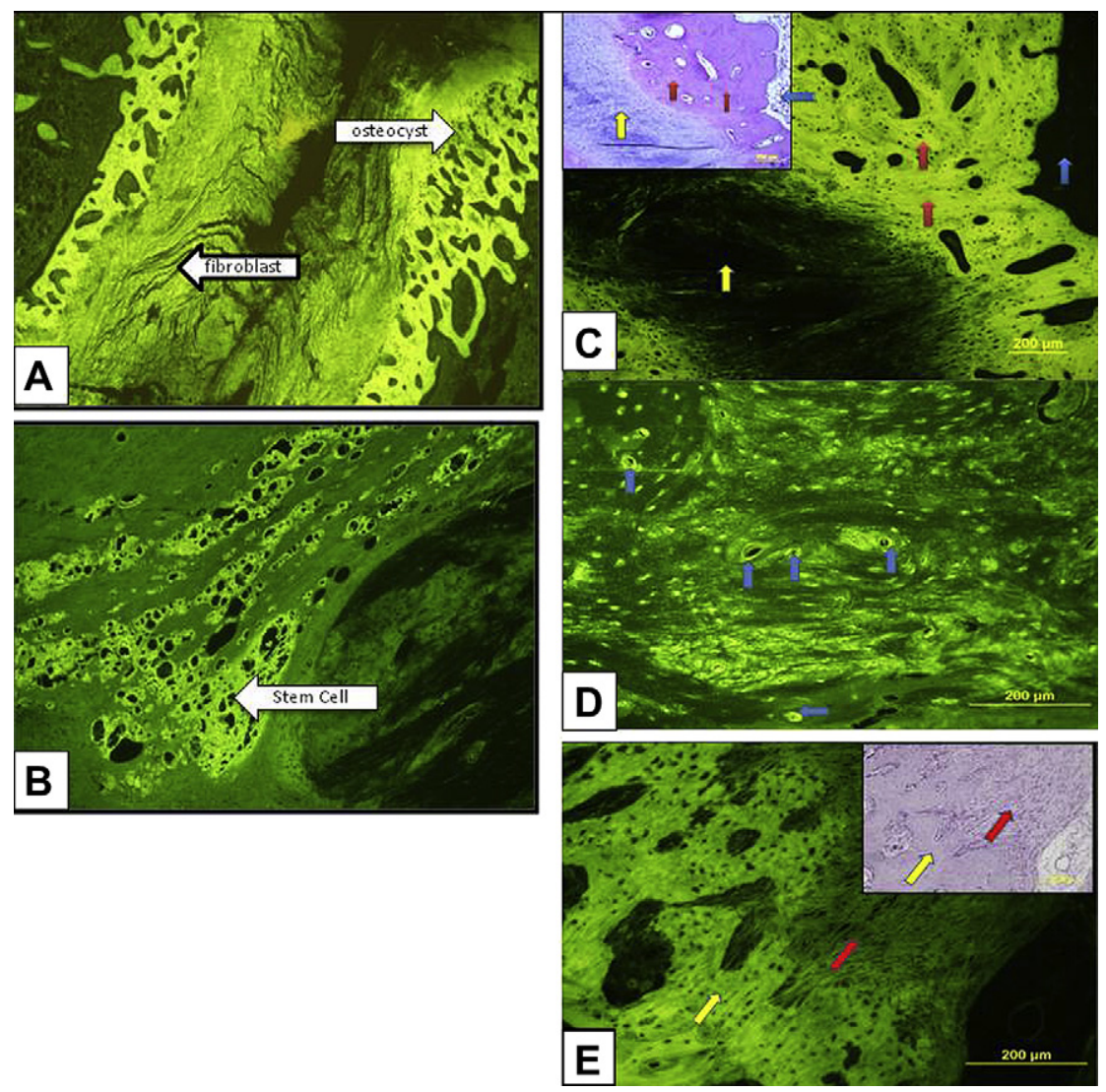

Figure 5. Presence of GFP in regenerated bone in groups II and III. (A) Group II. GFP-labeled and emitting fibroblasts and osteocytes. (B) Group II. GFP-labeled, undifferentiated stem cells. (C) Group III. Two different images taken from the same area. GFP-emitting osteocytes (red arrow), non-emitting chondrocytes (yellow arrow), non-emitting bone marrow cells (blue arrow). (Upper left, hematoxylin and eosin.) (D) Group III. GFP-labeled and emitting osteocytes (blue arrow). (E) Group III. Group that received differentiated stem cells. GFPemitting osteocytes (yellow arrow), non-emitting fibroblasts (red arrow). (Upper right, hematoxylin and eosin.)

was reported compared with group II and group III $(P=0.011$ and $P=0.005$, respectively). Consequently, cellular count analysis explains staging differences in healing between the groups.

Looking at the new ossifying average area ratios in square millimeters, highest ossification was in group III $(61 \%$, Figure $6 \mathrm{~B})$. This ratio is statistically significant compared with group I and group II $(P=$ 0.002 and $P=0.002$, respectively). The highest percentage of cartilage was measured in group III $(30 \%)$, and this mean value is statistically significant compared with group I and group II $(P=0.002$ and $P=0.002$, respectively).

\section{Immunohistochemical evaluations}

Osteoblasts synthesizing osteocalcin and osteopontin were labeled and shown by immunohistochemical staining in the prepared sections $(36,41)$. The number of cells staining positive for osteocalcin, which is considered specific for ossification, was found to be 24, 31 and 37 in groups I, II and III, respectively (Figure 7A). Following statistical analysis, a significant increase was observed in group II and group III compared with group I $(P=0.0001$ and $P=0.0002$, respectively). The number of osteopontin-positive cells in groups I, II and III was determined to be 20, 25 and 34, respectively. Following the statistical comparison of the results, group II and group III were observed to have significantly more osteopontin-positive cells compared with group I $(P=0.0001$ and $P=0.0002$, respectively) (Figure 7A). The number of positive stained cells was found to be higher in group II (Figure 7D,E) and group III (Figure $7 \mathrm{~F}, \mathrm{G}$ ) compared with group I (Figure 7B,C). This increase explains the reason for the high rate of ossification in groups II and III (Figure 7).

\section{Discussion}

Distraction osteogenesis, without the need of bone graft, provides simultaneous correction of the deformity by supplying force on the deformity during the treatment period and allows for new bone formation $(42,43)$. Ilizarov $(44)$ stated the importance of the stability of the frame that is placed for the 

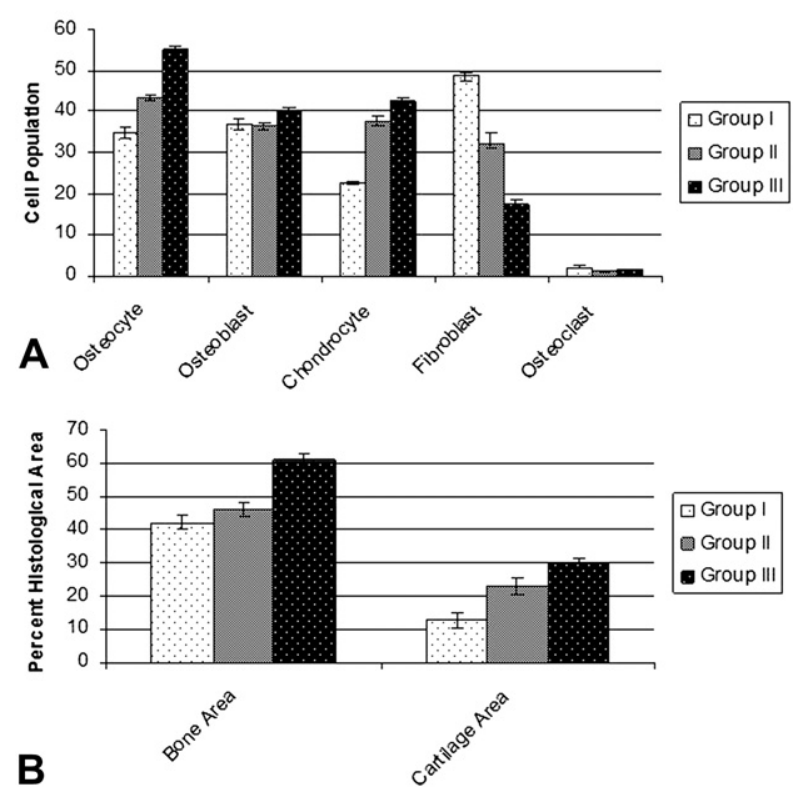

Figure 6. (A) Cell populations of osteocytes, osteoblasts, chondrocytes, fibroblasts and osteoclasts. (B) Bone and cartilage areas of groups I, II and III.

process of bone healing. The circular external fixator, when properly applied, stabilizes the bone fragments in all planes. However, it also allows for axial micromovements that stimulate osteogenesis. In our study, it was shown that the fixation system, composed of three bars, two coils and four pieces of Kirschner wire, allowed sufficient fixation in all subjects against the strong leg movements of the rabbits.

Distraction rate and rhythm are known to be very important in the maintenance of sufficient elongation $(43,44) . \mathrm{Li}$ et al. (45) demonstrated that distraction carried out with rabbits at a speed of $0.7 \mathrm{~mm} /$ day is the optimal rate for cell proliferation and bone formation. In our study, we achieved successful results using the same speed and rhythm, and there was no premature union or non-union in any subjects.

Distraction osteogenesis has significant importance in bone regeneration with its unique improvement mechanism. However, it can lead to undesirable outcomes, such as a long consolidation period and re-fractures that may occur during this period (approximately 1-2 months for each extension of $1 \mathrm{~cm})(9,46)$, pin loosening, collapse of callus, loss of elongation, malunion, non-union and infection $(4,9,46-48)$. Many studies have investigated how to stimulate the consolidation process and to increase bone formation. As the desired success has not been achieved in studies using growth factors, the importance of stem cells in bone regeneration has gained significance (15).

Adipose tissue-derived MSCs have significant therapeutic potential in various diseases. They can differentiate into various connective tissue lineages, including cartilage, tendon and bone (49). In the literature, there are many studies of distraction osteogenesis using bone marrow-derived MSCs $(42,46)$. However, the process of bone marrow extraction is inconvenient, and the number of obtained cells is insufficient. Also, cells that are repeatedly passaged to increase their number tend to become cancerous (50). Adipose tissue-derived MSCs are much greater in number and can be obtained easily with low donor site morbidity compared with bone marrow-derived MSCs (22). These characteristics of adipose tissue-derived MSCs allow them to be used in tissue engineering (51).

Kinoshita et al. (52) stated that it is vital to determine if the stem cells applied to the distracted area participate in new bone formation. In our study, we transfected MSCs with a GFP plasmid to observe if the MSCs contribute to the new bone formation and to identify the viability of the MSCs. After the 8-week consolidation period, the obtained bone samples were decalcified using ethylenediaminetetraacetic acid solution. On delayed de-calcification of the bone using ethylenediaminetetraacetic acid solution, $20 \%$ formic acid was used for de-calcification. It was observed that both methods had no negative effect on the emission of the cells under the fluorescent microscope.

In this study, bone regeneration was examined through radiologic, biomechanical and histopathologic approaches in three groups of New Zealand rabbits. For the radiologic evaluation of the newly formed bone in the distraction area, the most commonly used method in the literature for radiologic evaluations, the modified Lane and Sandhu scoring system, was used $(52,53)$. In this scoring system, bone occupancy rates, proximal and distal unions, medullary canal formation and cortex formation are of special importance. In the evaluations undertaken using this scoring system, the highest bone occupancy rates were observed in group III compared with the other groups. The bone occupancy rates in two rabbits in group III reached $100 \%$. This percentage was found to be lower in group II. Callus ossification was found significantly less in stem cell groups in group I. Medullary canal formation or full-fledged organization of the cortex was not determined in any of the rabbits because an 8-week waiting period is an insufficient time for the formation of medullary canal and cortex. Following the examination of the radiographs of the rabbits in our study, callus formation in the injected area was found to be more significant compared with other regions in three rabbits in group III. These findings support the idea that administration of osteogenic stem cells to callus area accelerate healing of bone. 

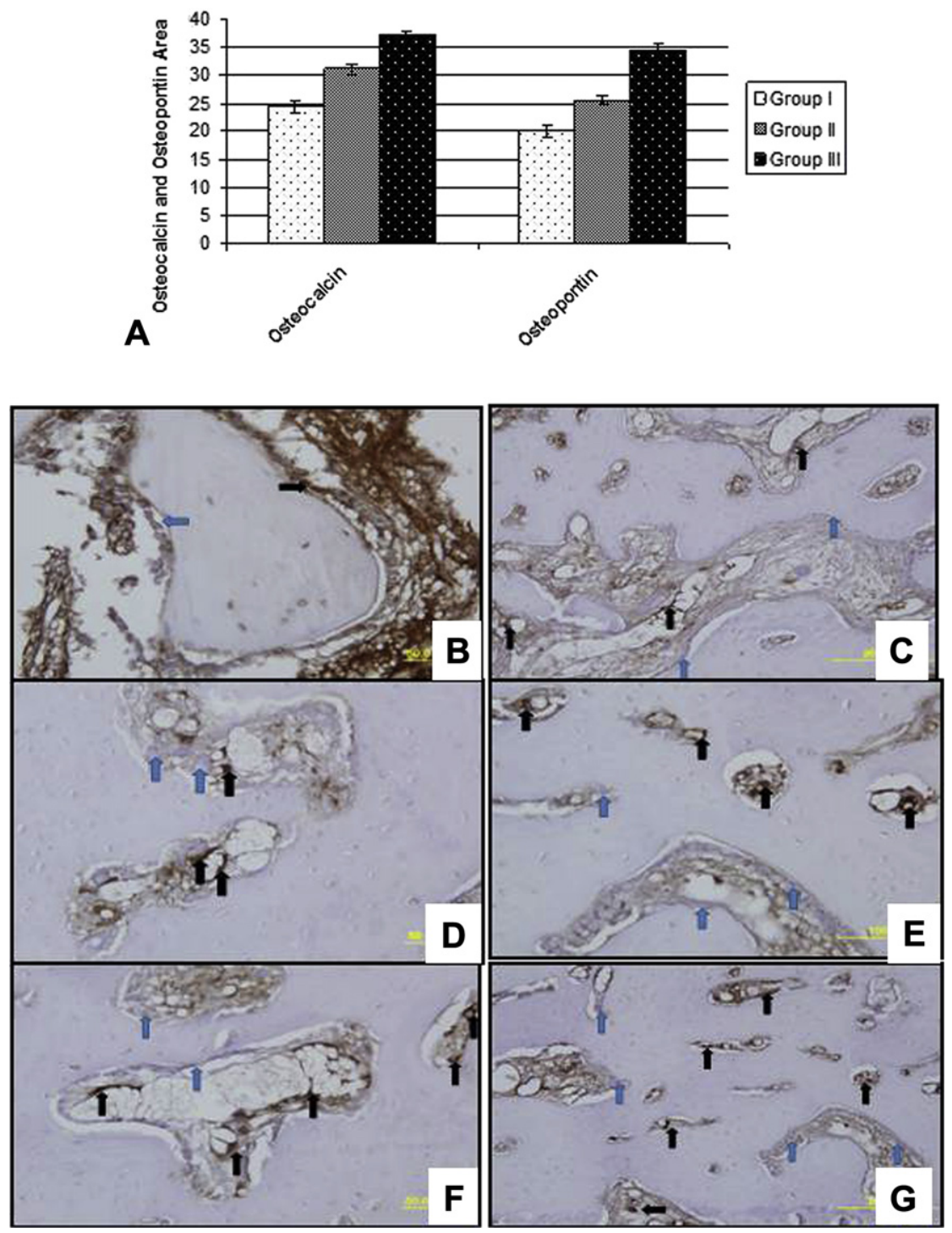

Figure 7. (A) Osteocalcin and osteopontin positive $(+)$ and negative $(-)$ areas in three groups. (B) Group I. Osteocalcin (+) cell (black arrow), osteocalcin (-) cell (blue arrow). (C) Group I. Osteopontin (+) cells (black arrow), osteopontin (-) cells (blue arrow). (D) Group II. Osteocalcin $(+)$ cells (black arrow), osteocalcin $(-)$ cells (blue arrow). (E) Group II. Osteopontin $(+)$ cells (black arrow), osteopontin $(-$ ) cells (blue arrow). (F) Group III. Osteocalcin (+) cells (black arrow), osteocalcin (-) cells (blue arrow). (G) Group III. Osteopontin (+) cells (black arrow), osteopontin (-) cells (blue arrow).

For biomechanical evaluations, $3 \mathrm{~cm}$ of bone tissue were extracted from the tibia of the rabbits by positioning the distracted region at the center. The extracted tissue was cleared away from the soft tissues and delivered to the biomechanical laboratory on sterile saline-soaked cotton. The results obtained from the device pressing at a speed of $1 \mathrm{~mm} / \mathrm{min}$ were transferred to the computer. Analysis of the results showed the highest scores were obtained in group III.

On histopathologic examinations in our study, a large proportion of the bone trabeculae were observed to be stretching parallel to the direction of distraction. Osteocytes were observed within the forming trabeculae, and osteoblasts were detected around the trabeculae $(34,40,52)$. The lamellar structure was determined to be more sparse and irregular in group I and group II compared with group III. On examination of the histologic preparations, no floating fragments that could occur secondary to osteotomy were observed in the fracture region. These fragments were prevented because osteotomy was carried out using a low-speed motor and the osteotomy area was washed with sterile saline after the surgery. In addition, the area was continuously cooled during the osteotomy process; necrotic areas that could form owing to high temperature were not encountered. Capillary structures that increased secondary to distraction osteogenesis were observed within the haversian canals. In addition, 
small numbers of large and small vessels were found in a large proportion of these materials. On analysis of the tissues using Masson's trichrome stain, the general appearance was observed to contain irregular connective tissue fibrils. Intense collagen deposition was also observed within these regions, and osteocytes were present in between the collagen fibrils. The amount of osteoid structure was found to be higher in group III compared with the other groups. Properties such as a lack of lamellar structure, incomplete formation of osteon structure and nonhomogeneous dispersion of collagen fibrils show the dominance of intramembranous-type ossification in our study. On examination of group II and group III using the fluorescent microscope, injected stem cells were observed to be emitting a GFP signal, and the viability of MSCs applied into the distraction area was confirmed. Fluorescent and light microscopic examination of the same region in group III showed the GFP-emitting cells to be mainly osteocytes, and a few osteoblasts were also detected. On fluorescent microscopic examination of the cells in group II, the GFP-emitting cells were observed to represent virtually all cell types found in the distraction area (osteocytes, osteoblasts, chondrocytes, fibroblasts and progenitor cells). As a result of this significant finding, it can be stated that instead of injecting only MSCs into the defective area, administration of osteogenically differentiated MSCs into the fracture region can contribute directly to bone healing.

On comparison of the average number of fibroblasts and osteoclasts per square millimeter, a significant decrease was observed in group I compared with groups II and III. The reduction in the number of fibroblasts likely occurred as a result of a change in the connective tissue into cartilage and bone tissue. The ossification process is characterized by an increase in the number of osteocytes, osteoblasts and chondrocytes and a decline in the number of fibroblasts and osteoclasts. The highest osteocyte and osteoblast values were observed in group III.

Examination of the bone and cartilage area ratios shows that an increase in the bone-to-cartilage ratio provides a comparison of cartilage areas secondary to endochondral ossification. With this parameter, the high rate of ossification seen in group III seems to support the positive effects of differentiated MSCs on bone formation. The numbers of cells staining positive for osteocalcin and osteopontin, which are specific markers of ossification, were found to be significantly higher in group II and group III compared with group I. All of the histopathologic examinations showed osteoblastic activity to be increased in group II; however, this increase was lower than in group III. In all histopathologic examinations and area measurements made to determine the degree of fracture healing, the highest scores were observed in group III, which received the calciumstoring, cytokine-secreting osteoblast-like cells.

In conclusion, the current findings showed that adipose tissue-derived, osteogenically differentiated MSCs accommodate the distraction process, and a large proportion of the stem cells applied into the distraction area remain viable and integrate into the bone formation process. As non-differentiated stem cells in group II differentiated into several cell types in vivo, their contribution to fracture healing was found to be lower compared with group III. As a result of the contributions made by osteogenic stem cells to fracture healing, it could be stated that the consolidation period of distraction osteogenesis could be shortened, and the fracture healing process could be accelerated using these stem cells.

\section{Acknowledgments}

This study was supported by Dokuz Eylul University, Scientific Research Council (MY) and by the Turkish Academy of Sciences, Outstanding Young Investigator Programme (YB). We thank the Biotechnology and Bioengineering Center staff of Izmir Institute of Technology for their help and technical support.

Author contributions are as follows: conception and design, OS, IK, MY, YB; financial support, $M Y$, YB; administrative support, MY, YB; provision of study material, OS, GC, ZC, ZD, IK, MY, YB; collection or assembly of data or both, OS, GC, ZC, $\mathrm{ZD}, \mathrm{IK}, \mathrm{MY}, \mathrm{YB}$; data analysis and interpretation, OS, GC, ZC, ZD, IK, MY, YB; manuscript writing, OS, GC, ZC, IK, YB; final approval of manuscript, OS, GC, IK, YB.

Disclosure of interest: The authors have no commercial, proprietary, or financial interest in the products or companies described in this article.

\section{References}

1. Mandu-Hrit $M$, Seifert E, Kotsiopriftis $M$, Lauzier D, Haque $\mathrm{T}$, Rohlicek C, et al. OP-1 injection increases VEGF expression but not angiogenesis in a rabbit model of distraction osteogenesis. Growth Factors. 2008;26: 143-51.

2. Ozdemir H, Akyildiz FF. Basic principles of circular external fixators in the treatment of bone defects and deformities. Acta Orthop Traumatol Turc. 2004;34:434-43.

3. Dimitriou R, Jones E, McGonagle D, Giannoudis PV. Bone regeneration: current concepts and future directions. BMC Med. 2011;9:66.

4. Paley D. Problems, obstacles, and complications of limb lengthening by the Ilizarov technique. Clin Orthop Relat Res. 1990;250:81-104. 
5. Wall ME, Rachlin A, Otey CA, Loboa EG. Human adiposederived adult stem cells upregulate palladin during osteogenesis and in response to cyclic tensile strain. Am J Physiol Cell Physiol. 2007;293:1532-8.

6. Shimazaki A, Inui K, Azuma Y, Nishimura N, Yamano Y. Low-intensity pulsed ultrasound accelerates bone maturation in distraction osteogenesis in rabbits. J Bone Joint Surg Br. 2000;82:1077-82.

7. Hagiwara T, Bell WH. Effect of electrical stimulation on mandibular distraction osteogenesis. J Craniomaxillofac Surg. 2000;28:12-9.

8. Cho BC, Moon JH, Chung HY, Park JW, Kweon IC, Kim IS. The bone regenerative effect of growth hormone on consolidation in mandibular distraction osteogenesis of a dog model. J Craniofac Surg. 2003;14:417-25.

9. Hamdy RC, Amako M, Beckman L, Kawaguchi M, Rauch F, Lauzier D, et al. Effects of osteogenic protein-1 on distraction osteogenesis in rabbits. Bone. 2003;33:248-55.

10. Rauch F, Lauzier D, Travers R, Glorieux F, Hamdy R. Effects of locally applied transforming growth factor-betal on distraction osteogenesis in a rabbit limb-lengthening model. Bone. 2000;26:619-24.

11. Yamane K, Okano T, Kishimoto H, Hagino H. Effect of ED71 on modeling of bone in distraction osteogenesis. Bone. 1999;24:187-93.

12. Hamanishi C, Yoshii T, Totani Y, Tanaka S. Bone mineral density of lengthened rabbit tibia is enhanced by transplantation of fresh autologous bone marrow cells: an experimental study using dual X-ray absorptiometry. Clin Orthop Relat Res. 1994;303:250-5.

13. Reddi AH. Bone morphogenetic proteins, bone marrow stromal cells, and mesenchymal stem cells. Maureen Owen revisited. Clin Orthop Relat Res. 1995;313:115-9.

14. Hagino T, Hamada Y. Accelerating bone formation and earlier healing after using demineralized bone matrix for limb lengthening in rabbits. J Orthop Res. 1999;17:232-7.

15. Qi M, Hu J, Zou S, Zhou H, Han L. Mandibular distraction osteogenesis enhanced by bone marrow mesenchymal stem cells in rats. J Craniomaxillofac Surg. 2006;34:283-9.

16. Pittenger MF, Mackay AM, Beck SC, Jaiswal RK, Douglas R, Mosca JD, et al. Multilineage potential of adult human mesenchymal stem cells. Science. 1999;284:143-7.

17. Rickard DJ, Kassem M, Hefferan TE, Sarkar G, Spelsberg TC, Riggs BL. Isolation and characterization of osteoblast precursor cells from human bone marrow. J Bone Miner Res. 1996;11:312-24.

18. Bruder SP, Jaiswal N, Haynesworth SE. Growth kinetics, self-renewal, and the osteogenic potential of purified human mesenchymal stem cells during extensive subcultivation and following cryopreservation. J Cell Biochem. 1997;64: 278-94.

19. Fernyhough ME, Hausman GJ, Guan LL, Okine E, Moore SS, Dodson MV. Mature adipocytes may be a source of stem cells for tissue engineering. Biochem Biophys Res Commun. 2008;368:455-7.

20. Howell JC, Lee W-H, Morrison P, Zhong J, Yoder MC, Srour EF. Pluripotent stem cells identified in multiple murine tissues. Ann N Y Acad Sci. 2003;996:158-73.

21. Arai $F$, Ohneda $O$, Miyamoto $T$, Zhang $X Q$, Suda $T$. Mesenchymal stem cells in perichondrium express activated leukocyte cell adhesion molecule and participate in bone marrow formation. J Exp Med. 2002;195:1549-63.

22. Zuk PA, Zhu M, Ashjian P, De Ugarte DA, Huang JI, Mizuno $\mathrm{H}$, et al. Human adipose tissue is a source of multipotent stem cells. Mol Biol Cell. 2002;13:4279-95.

23. Gronthos S, Zannettino ACW, Hay SJ, Shi S, Graves SE, Kortesidis A, et al. Molecular and cellular characterisation of highly purified stromal stem cells derived from human bone marrow. J Cell Sci. 2003;116:1827-35.

24. Hausman GJ, Campion DR. Histology of the stroma in developing rat subcutaneous adipose tissue. J Anim Sci. 1982; 55:1336-42.

25. Loffler G, Hauner H. Adipose tissue development: the role of precursor cells and adipogenic factors. Part II. The regulation of the adipogenic conversion by hormones and serum factors. Klin Wochenschr. 1987;65:812-7.

26. Boquest AC, Shahdadfar A, Brinchmann JE, Collas P. Isolation of stromal stem cells from human adipose tissue. Methods Mol Biol. 2006;325:35-46.

27. Zuk PA, Zhu M, Mizuno H, Huang J, Futrell JW, Katz AJ, et al. Multilineage cells from human adipose tissue: implications for cell-based therapies. Tissue Eng. 2001;7:211-28.

28. Hulth A. Current concepts of fracture healing. Clin Orthop Relat Res. 1989;249:265-84.

29. Sunay O, Ilker B, Denek Z, Yilmaz M. A practical dressing method to be used in experimental studies on the extremities of rabbits. Scientific Letter. Turk Klin Tip Bilim Derg. 2010; 30:2025-6.

30. Bieback K, Kern S, Kocaomer A, Ferlik K, Bugert P. Comparing mesenchymal stromal cells from different human tissues: bone marrow, adipose tissue and umbilical cord blood. Biomed Mater Eng. 2008;18:71-6.

31. Kozanoglu I, Boga C, Ozdogu H, Sozer O, Maytalman E, Yazici AC, et al. Human bone marrow mesenchymal cells express NG2: possible increase in discriminative ability of flow cytometry during mesenchymal stromal cell identification. Cytotherapy. 2009;11:527-33.

32. Baran Y, Ural AU, Avcu F, Sarper M, Elçi P, Pekel A. Optimization of transfection of green fluorescent protein in pursuing mesenchymal stem cells in vivo. Turk J Hematol. 2008;25:172-5.

33. Hua J, Yu H, Dong W, Yang C, Gao Z, Lei A, et al. Characterization of mesenchymal stem cells (MSCs) from human fetal lung: potential differentiation of germ cells. Tissue Cell. 2009;41:448-55.

34. Huddleston PM, Steckelberg JM, Hanssen AD, Rouse MS, Bolander ME, Patel R, et al. Ciprofloxacin inhibition of experimental fracture-healing. J Bone Joint Surg Am. 2000; $82: 161-73$.

35. Aronson J, Gao GG, Shen XC, McLaren SG, Skinner RA, Badger TM, et al. The effect of aging on distraction osteogenesis in the rat. J Orthop Res. 2001;19:421-7.

36. Perren DS, Brown EC, Aronson J, Skinner RA, Montague DC, Badger TM, et al. Immunohistochemical study of osteopontin express during distraction osteogenesis in the rat. J Histochem Cytochem. 2002;50:567-74.

37. Sen C, Gunes T, Erdem M, Koseoglu RD, Filiz NO. Effects of calcitonin and alendronate on distraction osteogenesis. Int Orthop. 2006;30:272-7.

38. Korkmaz M, Ozturk H, Bulut O, Unsaldi T, Kaloglu C. The effect of definitive continuous distraction amployed with the Ilizarov type external fixation system on fracture healing: an experimental rabbit model. Acta Orthop Traumatol Turc. 2005;39:245-57.

39. Isaksson H, van Donkelaar CC, Huiskes R, Yao J, Ito K. Determining the most important celluler characteristics for fracture healing using design of experimental methods. J Theor Biol. 2008;255:26-39.

40. Sen C, Erdem M, Gunes T, Koseoglu D, Filiz NO. Effects of diclofenac and tenoxicam an distraction osteogenesis. Arch Orthop Trauma Surg. 2007;127:153-9.

41. McKee MD, Pedraza CE, Kaartinen MT. Osteopontin and wound healing in bone. Cells Tissues Organs. 2011;194: 313-9. 
42. Richards M, Huibregtse BA, Caplan AI, Goulet JA, Goldstein SA. Marrow-derived progenitor cell injections enhance new bone formation during distraction. J Orthop Res. 1999;17:900-8.

43. Ilizarov GA. The tension-stress effect on the genesis and growth of tissues. Part I. The influence of stability of fixation and soft-tissue preservation. Clin Orthop Relat Res. 1989; 238:249-81.

44. Ilizarov GA. The tension-stress effect on the genesis and growth of tissues. Part II. The influence of the rate and frequency of distraction. Clin Orthop Relat Res. 1989;239: 263-85.

45. Li G, Simpson AH, Kenwright J, Triffitt JT. Assessment of cell proliferation in regenerating bone during distraction osteogenesis at different distraction rates. J Orthop Res. 1997; 15:765-72.

46. Shao Z, Liu B, Peng Q, Liu W, Liu Y, Liu R, et al. Transplantation of osteoblast-like cells to the distracted callus in the rabbit mandible. Plast Reconstr Surg. 2007;119:500-7.

47. Fischgrund J, Paley D, Suter C. Variables affecting time to bone healing during limb lengthening. Clin Orthop Relat Res. 1994;301:31-7.

48. Noonan KJ, Leyes M, Forriol F, Canadell J. Distraction osteogenesis of the lower extremity with use of monolateral external fixation: a study of two hundred and sixty-one femora and tibiae. J Bone Joint Surg Am. 1998;80:793-806.
49. Baksh D, Song L, Tuan RS. Adult mesenchymal stem cells: characterization, differentiation, and application in cell and gene therapy. J Cell Mol Med. 2004;8:301-16.

50. Danoviz ME, Bassaneze V, Nakamuta JS, dos SantosJunior GR, Saint-Clair D, Bajgelman MC, et al. Adipose tissue-derived stem cells from humans and mice differ in proliferative capacity and genome stability in long-term cultures. Stem Cells Dev. 2011;20:661-70.

51. Wang Q, Steigelman MB, Walker JA, Chen S, Hornsby PJ, Bohnenblust $\mathrm{ME}$, et al. In vitro osteogenic differentiation of adipose stem cells after lentiviral transduction with green fluorescent protein. J Craniofac Surg. 2009;20:2193-9.

52. Kinoshita K, Hibi H, Yamada Y, Ueda M. Promoted new bone formation in maxillary distraction osteogenesis using a tissue-engineered osteogenic material. J Craniofac Surg. 2008;19:80-7.

53. Karaoglu S, Baktir A, Kabak S, Arasi H. Experimental repair of segmental bone defects in rabbits by demineralized allograft covered by free autogenous periosteum. Injury. 2002;33: $679-83$.

\section{Supplementary data}

Supplementary data related to this article can be found online at http://dx.doi.org/10.1016/j.jcyt.2013.02.004 